\title{
INDUÇÃO: UMA REAVALIAÇÃO DAS CRÍTICAS POPPERIANAS
}

\author{
Túlio Roberto Xavier de Aguiar \\ Universidade Federal de Minas Gerais
}

Resumo: Neste artigo, eu examino as principais críticas de Popper ao uso das inferências indutivas em ciência, tentando identificar e separar os pressupostos e consequências usualmente presentes em posições indutivistas de sua tese nuclear, a saber, que casos positivos de uma hipótese dão apoio evidencial para ela. Tentamos mostrar que as críticas de Popper atingem um alvo difuso que pode ser chamado de pacote indutivista, sendo incertas quando dirigida à tese nuclear.

Palavras-chave: probabilidade, apoio evidencial, mente passiva, David Miller, verificacionismo

Abstract: In this article, we examine the main criticisms of Popper to the use of inductive inference in science, trying to identify and separate the assumptions and consequences usually present at inductivists positions of its nuclear thesis, namely that positive cases of a hypothesis give evidential support for it. We try to show that the criticism of Popper reach a diffuse target that can be called inductive package, being uncertain when directed to nuclear theory.

Keywords: probability, evidential support, passive mind, David Miller, verificationism

\section{Introdução}

Os enunciados universais sintéticos da forma "todos os A's são B's" traduzem aquela parte do nosso conhecimento que é realmente digna deste nome - a que permite ultrapassar a nossa limitada experiência. São estas afirmações irrestritas quanto ao espaço e ao tempo que conferem poder ao conhecimento humano e permitem que a ciência seja o empreendimento 
espantoso que é. Entretanto, um preço tem que ser pago pela busca desta universalidade. Na medida em que avançamos para além do experienciado, ingressamos no domínio do incerto, onde podemos falar, na melhor das hipóteses, de probabilidade. Este hiato entre o os enunciados universais que afirmam certas regularidades e os enunciados singulares que sumariam nossa experiência é responsável por boa parte das dificuldades com que se enfrenta a epistemologia. Teremos determinado tipo de epistemologia conforme a atitude que se tome perante este problema.

Com relação a isto, Hume percebeu com clareza estes dois fatos: a) a importância para o conhecimento humano de formular afirmações universais $^{1}$; b) a impossibilidade de se obter estas afirmações, de maneira unívoca, a partir da experiência. Toda a epistemologia posterior a Hume é uma tentativa direta ou indireta de contornar a interação destrutiva entre $a$ e $b$. Não há sequer um epistemólogo que não tenha sentido em maior ou menor grau a contundência da argumentação humeana acerca de $b$.

Existem basicamente cinco rotas de fuga para evitar o choque entre $a$ e $b: 1)$ abandonar as afirmações universais (hipóteses), não considerandoas relevantes para o conhecimento ${ }^{2} ; 2$ ) desconsiderar a experiência como sendo de vital importância para o conhecimento da realidade; 3) levar $b$ a sério e abandonar o projeto de construir um sistema que permita inferir, univocamente, enunciados universais a partir da evidência empírica; 4) admitir que embora unívoca, a passagem da evidência para enunciados universais não pode ser explicada em bases racionais; 5) substituir em $b$ a palavra "impossibilidade" por algo como "dificuldade extrema" e seguir tentando construir um sistema lógico que permita inferir enunciados universais da evidência empírica de forma unívoca (um sistema de lógica indutiva). O caminho 1) foi seguido por Mach e Carnap (1 $1^{\underline{a}}$ fase). Intelectualistas e convencionalistas ilustram o segundo caminho, ambos procuram julgar teorias por critérios a priori (clareza e distinção,

\footnotetext{
${ }_{1}$ Para sermos exatos, Hume considera inferências dos casos observados para o próximo caso ainda não observado. Por simplicidade, consideraremos apenas inferências para enunciados universais. Sobre generalizações do tipo causal, Hume diz: "(...) we ought not to receive as reasoning any of the observations we may make concerning identity, and the relations of time and place; since in none of them the mind can go beyond what is immediately present to the senses, either to discover the real existence or the relations of objects. 'Tis only causation, which produces such a connexion" (HUME [1739], p. 21). Ainda, "(...) o conhecimento das causas não é apenas o mais satisfatório, já que esta relação ou conexão é mais forte do que todas as outras, mas também mais instrutivo, pois é unicamente por este conhecimento que somos capazes de controlar eventos e governar o futuro" (HUME [1748], p.74).

$2 \mathrm{O}$ instrumentalismo pode, de certa forma, ser enquadrado neste primeiro caso, pois embora admitindo hipóteses, não lhes reconhecem como proposições dotadas de valor de verdade.
} 
simplicidade, etc.). O principal representante da terceira via é Karl Popper, que procura utilizar a experiência para testar as hipóteses sem se valer de inferências indutivas. A quarta solução para o problema é dada pelo próprio Hume. Ele pensa que é algo na natureza humana que opera a passagem do particular para o universal, considerando, entretanto, que não há justificação racional para tal passagem. A quinta tentativa consiste em se tentar derrotar o ceticismo humiano, construindo um sistema de lógica indutiva, sendo representada por Carnap, Reichenbach, Mill, Keynes, Bacon, etc. Esta divisão de escolas epistemológicas face ao problema levantado por Hume atesta, de forma eloquente, sua extrema importância.

Neste artigo, desejo examinar algumas das críticas que têm sido dirigidas contra a quinta via, a tentativa de construir um sistema de lógica indutiva. Chamaremos esta tendência de indutivismo. O principal adversário da escola indutivista é Karl Popper ( $3^{\text {a }}$ via) tanto pela radicalidade do seu anti-indutivismo, como pelo fato de que aceita, simultaneamente, a importância da experiência e das hipóteses, entendidas como enunciados universais. Neste ponto, ele está de acordo com o indutivismo. Assim, a epistemologia popperiana se opõe maximamente ao indutivismo, compartilhando o máximo com este. Ou seja, a oposição se dá estritamente quanto à questão da possibilidade de inferências indutivas (sendo nisto radical) e não, quanto ao papel desempenhado pela experiência ou pelas teorias.

Popper é, talvez, o filósofo que compreendeu com mais profundidade o alcance da crítica humiana acerca da indução. Ele, também, foi mais longe do que ninguém no caminho que leva a uma compreensão alternativa da ciência - que dispensa o apelo a qualquer tipo de procedimento indutivo. Não é nosso trabalho, aqui, examinar a adequação da proposta epistemológica de Popper. Também, não pretendo fazer uma defesa de uma epistemologia indutivista. Meu objetivo é bem mais limitado: examinar as críticas de Popper ao indutivismo e mostrar sua insuficiência.

\section{A Estratégia de Popper}

Seguindo atentamente a obra de Popper, podemos ver em ação uma estratégia peculiar de argumentação. Consiste em oferecer uma crítica do ponto de vista examinado através da crítica de diversos pressupostos e consequências deste. Podemos chamar este procedimento de multicriticismo ${ }^{3}$. Uma maneira, mais ou menos óbvia, de bloquear tal

${ }^{3}$ Recentemente, Boyd introduziu a noção de "pacotes filosóficos" como sendo um conjunto de teses que se agregam a uma tese central, quando esta é articulada para fazer face às principais 
espécie de crítica é examinando se os pressupostos e consequências, do ponto de vista sob exame, foram corretamente identificados. Além disto, deve-se avaliar em que medida a crítica aos pressupostos e consequências, quando cogente, é fatal para o ponto de vista examinado. O multicriticismo de Popper pode ser visto, em sua forma exemplar, na crítica ao determinismo e à indução. $\mathrm{O}$ nossa atenção recairá sobre o último caso.

Aqui, devemos fazer uma correção ao que foi dito acima. Popper também produziu uma crítica direta da indução, não só dos seus pressupostos e consequências. O que acontece é que a crítica direta é muito mais difícil de ser levada a cabo. O multicriticismo tem uma maior chance de se mostrar convincente levando a uma derrota relativamente fácil do ponto de vista adversário, derrota muitas vezes mais aparente do que real. De fato, em se fazendo um ataque indireto a uma posição pode-se facilmente perder o ponto em questão, a crítica atingindo alguma coisa, mas não a tese a que se destinava. É isto que acontece com a crítica popperiana à indução. Como veremos, esta crítica atinge de forma razoavelmente contundente alguns dos pressupostos e consequências da indução, sendo bastante mais controvertida quando dirigida ao núcleo da questão.

No que se segue, avaliaremos o conjunto de críticas indiretas de Popper à indução (multicriticismo) mais a sua crítica direta (prova de Popper e Miller).

\section{Críticas indiretas}

\section{A) Justificação da indução}

Seguindo a objeção clássica de Hume, Popper enfatiza as dificuldades de se justificar um princípio de indução. Vejamos o argumento.

As hipóteses científicas são sistemas de enunciados universais que pretendem exprimir certas leis da natureza. A inferência indutiva seria supostamente aquela que permitiria inferir estes enunciados universais da evidência empírica singular. Como, neste tipo de inferência, a premissa se refere a um número finito de indivíduos (pois a evidência empírica disponível é sempre finita) enquanto que a conclusão se refere a uma classe infinita, nós teremos mais na conclusão do que havia nas premissas. Para justificar este salto, seria preciso estabelecer um princípio de indução. Para o indutivista, dois 
caminhos estariam abertos no sentido de justificar este princípio: a) o recurso à lógica; b) o recurso à experiência.

Ora, como a inferência indutiva é reconhecidamente amplificadora - e por isto pode ter conclusão falsa com premissas verdadeiras - o princípio de indução não pode ser puramente lógico. Popper diz:

(...) se existisse algo assim como um princípio puramente analítico de indução, não haveria problema de indução, pois, em tal caso, todas as inferências indutivas teriam de ser encaradas como transformações puramente lógicas, exatamente como as inferências no campo da Lógica Dedutiva (POPPER [1934], p. 28) ${ }^{4}$.

Sendo assim, o princípio de indução deve ser um enunciado sintético, um enunciado cuja a negação é logicamente possível. Deve ser possível, então, justificá-lo com base na experiência. Esta tentativa, entretanto, conduz a um argumento circular ou a uma regressão infinita, dependendo da maneira de interpretá-lo. A sua estrutura seria algo como o seguinte:

O princípio de indução foi bem sucedido na ocasião $\mathrm{t}_{1}$.

$O$ princípio de indução foi bem sucedido na ocasião $t_{2}$.

O princípio de indução foi bem sucedido na ocasião $t_{n}$.

O princípio de indução é bem sucedido sempre.

Ora, o argumento acima é indutivo, necessitando de um princípio de indução para efetivá-lo. Se consideramos que este princípio de indução é do mesmo tipo do que ocorre nas premissas e na conclusão do nosso argumento, temos uma circularidade; esta é, grosso modo, a versão de Hume da crítica a uma justificação empírica de um princípio de indução. Podemos também, como faz Popper, interpretar o princípio de indução necessário para efetivar o nosso argumento como um princípio de indução de ordem superior, por se referir ao desempenho de um princípio de indução de ordem inferior e não, diretamente, ao curso da natureza. Mas, para justificar este meta-princípio de indução necessitaríamos de um princípio de indução de ordem ainda mais elevada e assim por diante. Assim, abre-se

4 " $(\ldots)$ if there were such a thing as a purely logical priciple of induction, there would be no problem of induction; for in this case, all inductive inferences would have to be regarded as purely logical or tautological transformations, just like inferences in deductive logic" (p. 28). 
diante de nós o abismo da regressão infinita. Em qualquer caso, temos que inferir do bom desempenho do princípio no passado para o seu bom desempenho no futuro, mas esta inferência supõe o princípio que está em questão.

Os argumentos humeanos que visam estabelecer a impossibilidade da indução são difíceis de serem derrotados, como atesta uma longa tradição. Não parecem suficientes, entretanto, para encerrar a discussão em torno da indução. Carnap, por exemplo, seguiu a estratégia de construir sistemas de indução localmente justificados, sem tentar responder ao desafio global de Hume. Ele tenta mostrar que o seu sistema é razoável, mas não tenta dar uma justificativa de porque, em geral, estamos justificados a fazer inferências indutivas.

Seja como for, falta na crítica de Popper o exame das tentativas naturalistas de justificativa da indução. O naturalista argumenta que os organismos são, grosso modo, capazes de fazer boas induções porque foi esta capacidade que permitiu-lhes sobreviver em seu ambiente. É verdade que o naturalismo enfrenta vários tipos de objeções. Por exemplo, parece vulnerável ao mesmo tipo de crítica acima esboçada quanto ao caráter circular de suas explicações, já que a teoria da evolução é uma teoria empírica. Estaríamos utilizando uma teoria empírica para justificar o suposto organum da ciências empíricas. Não está claro, entretanto, que este seja um círculo vicioso. É perfeitamente possível pensarmos em um apoio mútuo entre teorias e métodos. Aqui, basta ficar registrado que o exame de Popper é incompleto.

\section{B) Confirmacionismo/dogmatismo}

Popper associa à epistemologia indutivista (ou, ao "estilo indutivo") a tendência perniciosa para procurar apenas casos confirmadores para as teorias. Denominaremos tal tendência de "confirmacionismo" (Popper fala de "verificacionismo"). Popper assim se expressa:

O método de procurar verificações parecia-me pouco válido parecia-me, na verdade, ser o método típico de uma pseudociência (...). O método de procurar verificações não era apenas acrítico: promovia também uma atitude acrítica quer em quem expunha, quer em quem lia. Ameaçava, assim, destruir a atitude de racionalidade, de argumentação crítica (POPPER, 1983, p.180-181).

O confirmacionismo seria, assim, uma espécie de vício metodológico, que levaria facilmente a manutenção de posições débeis, sem ulterior exame crítico. Neste passo, Popper está criticando especificamente 
as teorias de Freud, Adler e Marx. Seus comentários, entretanto, são estendidos ao indutivismo genericamente compreendido.

Esta crítica, contudo, atinge apenas tangencialmente o indutivismo. $\mathrm{O}$ indutivismo afirma apenas que os casos positivos (instanciadores) de uma teoria a apoiam. A recomendação metodológica quanto ao valor para a pesquisa de dirigirmos nossa atenção prioritariamente para os casos confirmadores ou não é uma questão diversa. Além disso, boas regras metodológicas são coisas que os indutivistas dificilmente ignoram, pois a metodologia é um campo no qual a sua excelência é manifesta. Aqui, Bacon pode ser citado como prova, quando diz:

(...) o intelecto humano tem o erro peculiar e perpétuo de mais se mover excitar pelos eventos afirmativos que pelos negativos, quando deveria rigorosamente atentar para ambos. Vamos mais longe: na constituição de todo axioma verdadeiro, têm mais força as instâncias negativas (BACON [1620], p.24).

Este e diversos outros trechos ${ }^{5}$, referentes ao que Bacon chama ídolos da tribo, mostram a compatibilidade do indutivismo com uma regra metodológica que coloca ênfase nos casos adversos à teoria.

O confirmacionismo, visto como uma tendência psicológica humana ou como um método pouco crítico, pouco tem a ver com o problema da confirmação indutiva. Este último procura estabelecer simplesmente o valor de uma hipótese, dado um conjunto de evidências que lhe é favorável. É verdade que o sistema dedutivista de Popper, com ênfase exclusiva na evidência adversa, evita com mais eficiência o vício confirmacionista, mas um indutivista também pode fazê-lo mantendo-se indutivista.

Ainda que haja algo como uma metodologia confirmacionista, a crítica de Popper a esta tem um estranho sabor psicologístico. De fato, ele acusa tal método de promover uma atitude acrítica nas pessoas, acusação bastante estranha dado o declarado anti-psicologismo do nosso filósofo. Seria mais coerente com o tom geral de sua epistemologia, criticar a indutivismo apenas do ponto de vista lógico. (Adiante, veremos que Popper também produziu esta espécie de crítica).

\footnotetext{
5 "E bem se houve aquele que, ante um quadro pendurado no templo, como ex-voto dos que se salvaram dos perigos de um naufrágio, instado a dizer se ainda se recusava a aí reconhecer a providência dos deuses, indagou por sua vez: 'E onde estão pintados aqueles que, a despeito do seu voto, pereceram?" (BACON, [1620], p.23, Bacon se refere a uma passagem de Cícero, De Natura deorum, III, 37, § 89).
} 


\section{C) Mente passiva/conhecimento algorítmico}

Uma outra espécie de crítica que Popper dirige aos procedimentos indutivos se refere a uma determinada concepção de mente que lhe subjaz. Fundamentalmente, tal concepção encara a mente como tendo um alto grau de passividade.

Dentro desta tradição, a mente é vista como um órgão passivo, na medida em que se coloca na dependência do que é dado pelos sentidos. Além disso, a mente é vista como funcionando mecanicamente como uma grande calculadora. Vejamos traços desta concepção. Hume diz:

(...) todo poder criador do espírito não ultrapassa a faculdade de combinar, de transpor, aumentar ou de diminuir os materiais que nos foram fornecidos pelos sentidos e pela experiência (HUME [1748], p.11). ${ }^{6}$

e, ao nível do método ${ }^{7}$, Bacon:

Pois o nosso método de descoberta das ciências quase que iguala os engenhos e não deixa muita margem à excelência individual, pois tudo submete a regras rígidas e demonstrações (BACON [1620], p. 82).

Bacon fala, ainda, das percepções como "uvas maduras e da estação" das quais, quando pacientemente colhidas e comprimidas, fluirá o vinho puro do conhecimento. Popper denomina a teoria empirista da mente de "teoria do balde mental" e caracteriza-a como se segue:

O ponto de partida desta teoria é a doutrina persuasiva de que, antes de podermos conhecer ou dizer qualquer coisa acerca do mundo, devemos primeiro ter tido percepções - experiências dos sentidos. Supõe-se decorrer desta doutrina que o nosso conhecimento, a nossa experiência, consiste de percepções acumuladas (empirismo ingênuo) ou então de percepções assimiladas, separadas e

\footnotetext{
6 "(...) all this creative power of the mind amounts to no more than the faculty of compounding, transposing, augmenting, or diminishing the materials afforded us by the senses and experience".

${ }^{7}$ Bacon compara ainda os resultados de seu método com o resultado que se obtém ao traçar um círculo com um compasso.
} 
classificadas (concepção mantida, por Bacon e, de maneira mais radical, por Kant) (POPPER, 1972, p. 341). ${ }^{8}$

É claro que - dentro do empirismo e mesmo fora dele - este processo pode e frequentemente é muito mais complexo do que o descrito acima. Em Bacon, por exemplo, há um exaustivo processo de classificação e depuração do material dado aos sentidos. Em Hume, esta função é desempenhada pelo mecanismo de associação de idéias. No pensamento de Kant, o processo de conhecimento é bastante complexo: as percepções são a matéria prima que flui para dentro do balde onde sofre um processamento, uma espécie de digestão. A mente pode ser vista como um órgão que "digere" percepções. Popper acredita que mesmo em Kant o processo não difere essencialmente do preconizado por Bacon (adaptando a metáfora do "vinho puro do conhecimento" de Bacon, Popper fala de um "vinho fermentado" no caso de Kant) (POPPER, 1972, p. 342).

Popper acredita que, dentro desta concepção de mente, pouco espaço haveria para a criatividade humana. A mente teria a função de, no máximo, combinar o material fornecido pela observação. É neste sentido que Popper aponta a incompatibilidade entre a aprendizagem indutiva e a criatividade humana:

Indutivo é não-criativo (...). A teoria da indução é a teoria que tenta negar a criatividade do nosso espírito e dizer que tudo vem do exterior. Só precisamos de abrir os olhos para as coisas entrarem por eles (POPPER, 1982, p. 56). ${ }^{9}$

É interessante notar que a filosofia de Hume acaba sendo uma espécie de redução ao absurdo da concepção de uma mente passiva. De fato, é exatamente a tese de que se deve limitar ao que é dado à mente que gera $\mathrm{o}$ paradoxo, tornado manifesto por Hume, da conexão causal. O que Hume viu

\footnotetext{
8 "The starting point of this theory is the persuasive doctrine that before we can know or say anything about the world, we must first have had perceptions - sense experiences. It is supposed to follow from this doctrine that our knowledge, our experience, consists either of accumulated perceptions (naive empiricism) or else of assimilated, sorted, and classified perceptions (a view held by Bacon and, in more radical form, by Kant".

${ }^{9}$ No domínio da validade, a crítica de Popper segue o mesmo caminho. A indução é vista como uma maneira mecânica de submeter uma teoria a teste. Para Popper, o teste genuíno é sempre uma tentativa engenhosa de falsificar uma teoria, não há lugar para qualquer espécie de algoritmo de teste.
} 
é que só podemos perceber as coisas que estão, supostamente, em conexão, não a própria conexão. Então, como podemos descobrir conexões? Conjecturando, isto é, imaginando teorias que afirmam a existência de conexões entre certos tipos de fenômenos. É evidente que deste modo não poderemos ter certeza, o que não chega a ser problema, uma vez que podemos testar nossas teorias. Temos que supor, assim, uma mente intensamente ativa para que possamos lidar com conexões causais.

Embora tenha sido Reichenbach, um positivista, que introduziu a distinção entre contexto de descoberta e contexto de justificação, os filósofos positivistas falham em tornar tal distinção efetiva. A epistemologia positivista é sempre, no fundo, uma teoria da origem, da gênese, ou melhor, da constituição do conhecimento teórico. Popper põe isto a descoberto no seguinte trecho:

(...) Carnap introduz um método que nos permite "descobrir", ou antes, calcular, a melhor hipótese confirmada, isto é, a hipótese mais provável, com base na evidência dada. Mas isto significa, claro, que deixamos de ser livres para inventar uma hipótese (POPPER, 1983, p. 333). ${ }^{10}$

Por aparecer sob a forma de um cálculo, a indução probabilística causa a impressão de que estamos diante de um método de teste, quando na verdade é um método genético. Assim, Popper censura a tentativa de se construir um sistema de indução probabilística, pois:

A indução tem como resultado não ser um método de testar uma conjectura ou de avaliar o resultado do teste; antes se torna um método de calcular a melhor teoria por uma inferência indutiva (Idem, p. 335). ${ }^{11}$

Embora a crítica popperiana à concepção de uma mente passiva e à idéia de se reduzir o conhecimento a um processo algorítmico tenha seus méritos, não fica claro qual o seu impacto sobre a perspectiva indutivista.

10 "(...) Carnap introduces a method which allows us to 'discover', or rather to calculate, the best confirmed hypothesis, i.e., the most probable hypothesis, on given evidence. But this means, of course, that we are no longer free to invent a hypothesis" (Tradução nossa).

11 "Induction turns out not to be a method of testing a conjecture or of assessing the result of the test; rather, it becomesa method of calculating the best theory by an inductive inference". (Tradução nossa). 
O projeto indutivista pode e deve ser pensado como um esforço para estabelecer, progressivamente, algumas regras que permitam avaliar certas hipóteses face a uma evidência favorável. Isto não é negar a criatividade do espírito humano, pois estas regras pretendem apenas construir modelos aproximados da mente em seu bom funcionamento. O conjunto de regras que compõem este modelo pode ser modificado por inclusão de novas regras e refinamento das antigas, na medida em que novas maneiras de raciocinar ganham aceitação através de seu sucesso no empreendimento científico. E, deve-se notar, que esta demanda para estabelecer cânones do bom raciocínio é bastante compreensível. De fato, negar que se possa identificar certos padrões de bom raciocínio equivale a assumir que podemos extrair informações da natureza de uma maneira um tanto casual. Isto, por sua vez, parece levar a suposição - bastante contra-intuitiva - de que a natureza é bastante pródiga em revelar seus segredos. Dentro da suposição mais realista de que é bastante difícil aprender o funcionamento da natureza, só restaria replicar que existem meios de obter sucesso no empreendimento científico (nem todos os meios seriam bem sucedidos), mas que estes não possuem características em comum. Novamente, a idéia de que existem uma pluralidade de procedimentos, sem relação entre si, que permitem explorar a natureza parece favorecer a visão de uma natureza que se revela muito facilmente. Há muitas maneiras pelas quais uma teoria pode ser ruim, mas não existem tantos caminhos abertos para as boas teorias. É isto que torna a idéia de um método científico tão plausível - o método busca codificar os atributos que devem ser possuídos por uma boa teoria.

Popper é levado a abominar a sugestão de o conhecimento pode ser parcialmente algoritmizado devido a sua visão romântica do empreendimento científico. Em suas Replies, por exemplo, ele é explícito a respeito:

Mas com todo respeito pelos cientistas menores, eu desejo comunicar aqui uma idéia heróica e romântica da ciência e seus trabalhadores: homens que humildemente devotaram-se a procura da verdade, ao crescimento de nosso conhecimento; homens cuja a vida consistiu em uma aventura de idéias ousadas (POPPER, 1974, p. 977).

Popper pensa o empreendimento científico como um jogo entre a proposição de teorias ousadas e especulativas e a rigorosa tentativa de eliminá-las, caracterização que realmente torna a ciência uma atividade heróica. Resta saber se esta bela imagem reflete minimamente a realidade. A ciência, pensa Popper, é um empreendimento tipicamente 
humano, isto é, humano na medida em que não poderia ser realizada por uma máquina. Os atributos distintivos do homem - na medida em que se opõe a uma máquina - que seriam relevantes para a ciência, segundo a citação acima, seriam a criatividade e a coragem. Coragem para sustentar teorias arriscadas e para abandoná-las quando for o caso. Criatividade para idear estas mesmas teorias e para produzir testes capazes de submeter nossas idéias a uma seleção rigorosa.

O que precisamos indagar é se os atributos acima descritos são realmente necessários para a ciência e se os atributos necessários para a atividade científica são tão peculiarmente humanos. A coragem não parece desempenhar nenhum papel essencial para um bom processo cognitivo, teorias ousadas são apenas teorias que avançam muito para além da evidência ${ }^{12}$. Evidentemente, no caso humano, a coragem pode desempenhar um papel importante, mas isto é fortuito dentro do processo cognitivo enquanto tal. E quanto a criatividade? Aqui, cabe observar que as considerações de Popper são muito pouco desenvolvidas para que se tenha uma visão clara de sua opinião. Devemos nos perguntar até que ponto o que chamamos de criatividade - enquanto atributo indispensável para a boa ciência - não poderia ser simulado em máquinas. Evidentemente, podemos dizer que existe alguma coisa chamada "criatividade" humana que não poderia ser simulada em uma máquina (pode-se até mesmo definir criatividade assim). Mas, seria esta característica humana essencial para a boa cognição? Para um teórico da A.I. a resposta é negativa. Um pesquisador em inteligência artificial como Herbert Simon falando daqueles que resistem a idéia de que máquinas podem ser inteligentes e criativas diz:

Eles tem agarrado e sustentado um quadro romântico da mente humana que atribui a ela capacidades que ela simplesmente não possui - nem mesmo as mentes de Mozart e Einstein, para não falar do resto de nós, pobres mortais (SIMON, 1995, p. 38. Tradução nossa).

Assim, ainda que alguns atributos especificamente humanos como criatividade e coragem possam ter desempenhado um papel importante na construção efetiva da ciência, não está claro que este

12 Popper não tem uma definição melhor de ousadia. Assim, ousadia, entendida como trancendência em relação à evidência, pode perfeitamente ser simulada por uma máquina. 
processo não possa ser reconstruído por meio de procedimentos indutivos.

\section{D) Base empírica}

Popper considera que um pressuposto fundamental do indutivismo é supor a existência de uma base empírica segura a partir da qual induções poderiam ser realizadas. Fundamentalmente, esta base empírica seria segura por ser livre de teorias. É conhecida a crítica popperiana a esta suposta segurança e neutralidade da base empírica. Para Popper, todos os enunciados que empregamos são teóricos em algum grau. Isto valeria mesmo para enunciados que descrevem propriedades observáveis das coisas. Com relação a isto, Popper diz:

Os enunciados singulares transcendem a experiência porque os termos universais, que neles ocorrem normalmente, acarretam uma disposição de agir de maneira legalóide (POPPER, 1934, p. 425).

Agora, esta conclusão é universalmente aceita dentro da epistemologia contemporânea, sendo quase um truísmo. $\mathrm{O}$ mesmo não se pode dizer das consequências que Popper dela extrai. Os comentários que ele faz em torno da questão da base empírica mostram que ele está sempre pensando em uma forma fundacionista de indutivismo, onde a evidência empírica de certa forma prova a hipótese sob consideração. Apenas, seria uma prova enfraquecida, já que o que está em jogo agora são hipóteses meramente prováveis. Para que isto seja assim, a evidência empírica deveria ser considerada como certa. Em conexão com este fato, é conhecida a famosa passagem de C.I. Lewis onde ele diz " if anything is to be probable, then something must be certain" (ver JEFFREY, 1992, p. 68). É curioso, entretanto, que precisamente no ponto onde Popper acusa as epistemologias probabilistas de serem fundacionistas, dizendo que nenhum indutivista considerou o caso onde a própria evidência é incerta, o editor (Bartley) coloca uma lacônica nota com referência ao cap. 11 de The Logic of Decision de R. Jeffrey. É precisamente neste capítulo que Jeffrey desenvolve uma teoria do processamento da evidência incerta. Dentro desta perspectiva, conhecida como probabilismo radical, hipóteses podem ser probabilizadas através de evidências elas mesmas prováveis. Se esta teoria é coerente ou não, é um problema que não cabe examinar aqui.

O que torna a argumentação de Popper insuficiente é que ele condena o indutivismo através de sua usual pressuposição de segurança da base empírica. O problema é que para que este argumento fosse cogente seria preciso mostrar que este pressuposto do indutivismo é não só usual, mas 
também necessário, coisa que o criticismo de Popper está longe de nos fornecer. De fato, não é claro que não se possa fazer induções a partir de evidências empíricas incertas. É uma objeção costumeira ao sistema popperiano a de que uma vez admitida a falibilidade da base empírica, o processo de falsificação estaria irremediavelmente comprometido. A resposta, também costumeira, para isto é que como o framework popperiano é nãojustificacionista, nenhum problema se coloca. Como não se está tentando provar nada, não há problema em se pensar o processo de falsificação como um processo em que conjecturas controlam conjecturas. $\mathrm{O}$ que daria efetividade a este processo seria que as conjecturas utilizadas para testar (evidência observacional) são menos problemáticas do que as conjecturas sob teste (teorias). Se este é um movimento legítimo para Popper, não é claro porque, em princípio, o mesmo movimento não poderia ser feito pelos indutivistas. Eles poderiam dizer que conjecturas são probabilizadas por conjecturas. A efetividade (ou possível efetividade) deste processo se deveria ao mesmo fato já assinalado: conjecturas menos problemáticas controlam conjecturas mais problemáticas. É claro que um sistema de lógica indutiva que admita evidência incerta pode se mostrar, na prática, irrealizável ou de construção muito difícil. Mas, seria necessário mostrar muito mais: que a admissão de uma base empírica insegura arruina o projeto de construção de uma lógica indutiva. É provável que os únicos argumentos de peso que se possam avançar neste caso são os mesmos já avançados contra a forma clássica de indução - fundamentalmente, os argumentos de Hume. Os argumentos humeanos são por certo poderosos, mas o que deveria ser mostrado é que a admissão de observações inseguras criam novos problemas de princípio. Problemas meramente técnicos é de se supor que sejam enfrentados satisfatoriamente pelos indutivistas, pois mesmo os seus críticos reconhecem sua grande capacidade no enfrentamento de questões dessa natureza.

\section{Crítica direta: a impossibilidade da indução probabilística}

Popper dedicou diversos trabalhos à crítica da chamada indução probabilística. Seus esforços nesta direção culminaram com dois trabalhos em parceria com David Miller: "A proof of the impossibility of inductive probability" (1983) e "Why Probabilistic Support is not Inductive" (1987). Nestes dois polêmicos artigos, Popper e Miller (doravante, apenas P\&M) argumentam que havendo uma dependência probabilística entre uma hipótese e sua evidência empírica, esta dependência não pode ser de natureza indutiva. Desde que P\&M avançaram seu argumento em 1983, desencadeou-se uma polêmica de proporções poucas vezes observadas na história da filosofia. As 
réplicas (favoráveis ou não) sucederam-se umas às outras em quantidade espantosa. A correção matemática da prova nunca foi colocada em questão mas sim o seu significado e seus pressupostos. Para nossa exposição, utilizaremos apenas P\&M (1987) por ser o trabalho mais completo e elucidativo. Não nos envolveremos com a prova propriamente dita e sim com sua idéia mestra e seu significado.

A tese de P\&M é resumida logo no início do artigo da seguinte maneira:

Embora a evidência possa levantar a probabilidade de uma hipótese acima do valor medido em relação ao conhecimento de fundo apenas, cada aumento desta natureza na probabilidade tem que ser atribuído inteiramente às conexões dedutivas que existem entre a hipótese e a evidência (p. 569). ${ }^{13}$

Assim, o excesso da probabilidade posterior de uma hipótese em relação a sua probabilidade anterior, para utilizar a terminologia bayesiana, não pode se dever, segundo $\mathrm{P} \& \mathrm{M}$, a um nexo indutivo entre a evidência e a hipótese.

$\mathrm{O}$ argumento de $\mathrm{P} \& \mathrm{M}$ corre, em linhas gerais, como se segue. Toda hipótese $h$ pode ser fatorada, com respeito à evidência $e$, em duas partes, a saber: $\sim e v h$ e $h v e$. Ou seja, $h$ pode ser escrita como $h=(\sim e v h)$. $(h v e)$, ou ainda como $h=(e \supset h) .(h \vee e)^{14}$.

É uma reivindicação de P\&M que a parte amplificativa de $h$ em relação a $e$ é $\sim e v h$, sendo que a outra parte ( $h v e$ ) é claramente acarretada por $e$. Assim, $h \vee e$ mantém um nexo dedutivo com a evidência $e$, não ultrapassando esta em conteúdo. Já $\sim e v h$, não sendo dedutivamente acarretado por $e$, é a parte de $h$ que vai além da evidência, estando aí localizado o excesso de conteúdo de $h$ com respeito a $e$. A estratégia de P\&M, então, é mostrar que a parte amplificativa de $h$ é probabilisticamente contrasuportada (countersupported) por $e$, isto é, a evidência abaixa (em vez de levantar) a probabilidade de $\sim e v h$. Este fato pode ser expresso pela desigualdade $p(\sim e v h \mid e)-p(\sim e v h)<0^{15}$. Este resultado é obtido por P\&M através dos axiomas da teoria das probabilidades e de procedimentos

\footnotetext{
13 "Although evidence may raise the probability of a hypothesis above the value it achieves on background knowledege alone, every such increase in probability has to be attributed entirely to the deductive connections that exist between the hypothesis and the evidence ".

14 Os símbolos lógicos utilizados no texto, tais como "v", ".", "つ" denotam os usuais operadores lógicos do cálculo setencial. A fatoração de $h$ utiliza a bem conhecida equivalência lógica $p=$ $[(\sim q \vee p) .(p \vee q)]$. O símbolo "=" está sendo usado no sentido de equivalência lógica.

${ }^{15} \mathrm{P}(\mathrm{a} \mid \mathrm{b})$ denota a probabilidade condicional de $a$ dado $b$.Erro! Indicador não definido.
} 
matemáticos usuais, não sendo controverso (do ponto de vista estritamente matemático).

P\&M reivindicam ter mostrado que, embora $e$ suporte probabilisticamente $h$ (já que $p(h \mid e)>p(h))^{16}$, e contra-suporta a parte de $h$ que contém tudo de $h$ que vai além de $e$, isto é, $\sim e v h$. Das várias críticas avançadas contra o argumento de P\&M, o tipo mais interessante é o que desafia a reivindicação de que " $\sim e v h$ contém tudo de $h$ que vai além de $e$ ".

Fazendo uso da álgebra das classes de consequências de Tarski também usado por P\&M - Michael Redhead argumenta que em geral temos $C n(h) \neq C n(\sim e \vee h) \cup C n(h \vee e)(*)$.

Colocando isto em palavras, podemos dizer que existem certas consequências de $h$ que não são consequências nem de $\sim e v h$ nem de $h v e$ tomadas individualmente. Há uma parte do conteúdo de $h$ que só pode ser gerada pelos dois fatores conjuntamente. Redhead concorda que $h v e$ capta a parte de $h$ que está compreendida em $e$ já que se $h$ acarreta $e, h v e$ é logicamente equivalente a $e$ e, portanto, $[\mathrm{Cn}(\mathrm{h}$ v e $)=\mathrm{Cn}(\mathrm{e})] \subset \mathrm{Cn}(\mathrm{h})$. Entretanto, Redhead conclui, tendo em vista (*), que embora $\sim e v$ capte uma parte de $h$ que vai além de $e$, não capta tudo de $h$ que vai além de $e$ (cf. REDHEAD, 1985, p. 186-90). Popper concorda com estas objeções, mas replica que os objetores falham em exibir um exemplo de uma parte de $h$ que seja probabilisticamente apoiada pela evidência $e$ sem, contudo, manter com esta qualquer relação dedutiva.

Uma outra objeção, devida a Howson e Urbach (HOWSON e URBACH, 1993, p. 396), consiste em observar que, do ponto de vista de $\mathrm{P} \& \mathrm{M}$, o fato de $e$ abaixar a probabilidade de $\sim e v h$ é tão ruim quanto seria se o resultado fosse um aumento. De fato, em ambos os casos a evidência $e$ estaria dando informação a respeito de algo que a transcende ${ }^{17}$. De um ponto de vista não-indutivista, a evidência empírica não permite que transitemos para além dela, seja de que maneira for. Assim, P\&M teriam mostrado algo como a validade da contra-indução. Nós desconhecemos se Popper respondeu a esta objeção. Entretanto, pensamos que a resposta poderia ser a seguinte. Assume-se, como uma espécie de tese de absurdo, que a indução pode ser conjugada com o cálculo das probabilidades. Então, isola-se a parte de h que amplifica (ou transcende) a evidência e, observando-se que esta contra-

\footnotetext{
160 suporte que $h$ recebe de $e$, neste caso, reflete apenas o suporte de e para si mesmo. De fato, na fatoração de $h, h v$ e, é equivalente a e (sob a condição de que $h$ acarrete e ), refletindo o suporte que e dá a si mesmo.

17 Se quiséssemos colocar isto em termos Humeanos, poderíamos dizer que os casos observados não podem nos dar qualquer informação acerca da probabilidade dos casos não observados, seja positiva, seja negativa.
} 
suporta aquela. Isto nos coloca diante de um resultado inesperado, levando ao abandono da suposição de que a indução possa ser formulada com ajuda do cálculo das probabilidades. É uma conhecida tese de Popper que a indução, de qualquer espécie, não existe. Tendo esta tese em mente, como parece ser o caso de Urbach e Howson quando fazem a crítica acima, o resultado de P\&M é ruim, pois a contra-indução é uma espécie de indução. Mas a tese geral assumida por $\mathrm{P} \& \mathrm{M}$, no trabalho que estamos considerando, é que a indução não pode ser adequadamente codificada dentro do cálculo das probabilidades. Assim, a contra-dependência funciona como uma espécie de redução ao absurdo da posição que pretende conjugar indução e probabilidade, não sendo propriamente uma prova da validade da contra-indução.

De qualquer modo, podemos ver que a prova de P\&M é bastante controversa e de difícil avaliação. Não é muito fácil ver o que a prova estabelece. Deve-se atentar, ainda, que P\&M observam que o seu trabalho deixa em aberto a possibilidade da construção de uma lógica indutiva sem o uso do cálculo de probabilidades.

Concluindo, pensamos ter mostrado que a crítica de Popper à indução atinge um alvo difuso que poderia ser chamado de "pacote indutivista" (o próprio Popper fala de "estilo indutivo"), sendo pouco claro qual o impacto de sua crítica sobre a tese indutivista central de que uma hipótese pode ser apoiada por seus casos positivos.

\section{Referências}

BACON, F. Novum Organum. São Paulo: Editora Abril, 1984. [1620] (Col. "Os Pensadores").

BOYD. "Constructivism, Realism, and Philosophical Method". In: EARMAN, J. (ed.) Inference, Explanation and other Frustrations. Los Angeles: University of California Press, 1992.

JEFFREY, R. Probability and the Art of Judgment. Cambridge: Cambridge University Press, 1992.

REDHEAD. "On Impossibility of Inductive Probability". British Journal for the Philosophy of Science, vol. 36, 1985, p. 185-91.

HOWSON, C. \& URBACH, P. Scientific Reasoning: The Bayesian Approach. Chicago and La Salle: Open Court, 1993.

HUME, D. An Enquiry Concerning Human Understanding. Indianapolis: Hackett Publishing Company, 1977 [1748].

POPPER, K. \& MILLER, D. "A proof of the impossibility of inductive probability”. Nature, 302, 1983, p. 687-688. 
POPPER, K. \& MILLER, D "Why Probabilistic Support is not Inductive". Phil. Trans. R. Soc. Lond., 1987, vol. 321, no. 1562, p. 569591.

POPPER, K. The Logic of Scientific Discovery. London: Routledge, 1980 (reimpressão de 1992) [1934].

. Objective Knowledge: An Evolutionary Approach. London:

Oxford University Press, 1975. Conhecimento Objetivo. Tradução Milton Amado Belo Horizonte: Itatiaia/Edusp, 1975. [1972].

. "Replies to my critics". In: SCHILPP (ed.). The philosophy of

Karl Popper. La Salle: Open Court, 1974, vol. 2.

. Sociedade Aberta, Universo Aberto. (Entrevista conduzida por

Franz Kreuzer). Lisboa: D. Quixote, 1987 [1982].

. Realism and the Aim of Science (Postscript to the Logic of

Scientific Discovery, vol. 1). London: Hutchinson, 1985 [1983].

SIMON, H. "Machine as Mind". In: FORD, K. (ed.). Android Epistemology. Menlo Park, Mit Press, 1995. 